\title{
A PROTEÇÃO DOS DESLOCADOS INTERNOS NA SOCIEDADE INTERNACIONAL: EVOLUÇÃO CONCEITUAL E NORMATIVA
}

\author{
Maria Beatriz Bonna Nogueira ${ }^{1}$
}

\begin{abstract}
Resumo: Os deslocados internos são um dos principais grupos vulneráveis para os quais se destinam ações de proteção humanitária internacional. Atualmente, estima-se que existam cerca de 33.3 milhões de pessoas deslocadas internamente, em razão de conflitos armados, violência generalizada e violações sistemáticas de direitos humanos. Os deslocados internos, no entanto, não eram reconhecidos como categoria específica até do final dos anos 80 e tampouco havia qualquer arranjo normativo ou institucional voltado à sua proteção e assistência. O presente artigo apresentará o caminho percorrido pelos deslocados internos para sua consolidação como categoria internacional de proteção, partindo de um vácuo conceitual anos 70 , passando pela sua identificação com refugiados em potencial nos anos $80 \mathrm{e}$ culminando no reconhecimento internacional das suas vulnerabilidades específicas, direitos e prerrogativas de proteção dos anos 90 em diante. Argumentará ainda que os deslocados internos conformam uma categoria típica da sociedade internacional e que só poderia ser gestada em sua estrutura.
\end{abstract}

Palavras-chave: Deslocados internos. Refugiados. Nações Unidas. Sociedade internacional.

Abstract: Internally displaced persons are one of the main groups to which international humanitarian protection is provided. It is estimated nowadays that around 33.3

1 Mestre em Migração Forçada (Oxford) e em Direitos Humanos (LSE). Doutoranda em Relações Internacionais pela Universidade de Brasília. Atuou como Oficial de Elegibilidade no Comitê Nacional para os Refugiados (CONARE) e como Chefe da Assessora Internacional da Secretaria de Direitos Humanos da Presidência da República (SDH/PR). 
million people are internally displaced due to armed conflicts, generalized violence and systematic human rights violations. Those internally displaced persons, however, were not recognized as a specific category until the late 1980s nor there was any normative or institutional arrangement devoted to their protection and assistance. The present article shall present the path followed by internally displaced persons towards their consolidation as an international protection category. It shall begin with the conceptual vacuum prevalent in the 1970s, going through their identification as potential refugees in the 1980s and finally reaching the international recognition of their specific vulnerabilities, rights and protection prerogatives from the 1990s on. It shall further argue that internally displaced persons form a category which is typical of the international society and which could only be established within its structure.

Keywords: Internally displaced persons. Refugees. United Nations. International society.

\section{INTRODUÇÃO}

Em 2 de outubro de 2013, o Conselho de Segurança da Organização das Nações Unidas (ONU) publicou nota pública sobre a situação humanitária na Síria que contém o seguinte trecho:

O Conselho de Segurança está consternado com o inaceitável nível da escalada de violência e da morte de mais de 100.000 pessoas na Síria, conforme relatado pelo Secretário-Geral das $\mathrm{Na}$ ções Unidas e o Alto Comissariado das Nações Unidas para os Direitos Humanos. O Conselho está gravemente alarmado com a deterioração significativa e rápida da situação humanitária na Síria. Ele observa com grande preocupação que vários milhões de sírios, em particular os deslocados internos, quase metade dos quais são crianças, precisam de assistência humanitária imediata e que, sem o incremento urgente da ação humanitária, suas vidas estarão em risco ${ }^{2}$. (grifo nosso)

Na mesma linha, o Alto Comissariado das Nações Unidas para os Refugiados (ACNUR) caracteriza a crise síria como "a maior tragédia humanitária desse século" com base nos seguintes dados: 2 milhões de refugiados e 4.25 milhões de deslocados internos ${ }^{3}$.

2 UN SECURITY COUNCIL. Statement [made on behalf of the Security Council, at the 7039th meeting, 2 Oct. 2013, in connection with the Council's consideration of the item entitled "The situation in the Middle East"], 2 out. 2013, S/PRST/2013/15. Disponível em: <http://www.refworld.org/docid/524d32c04.html>. Acesso em: dez. 2013.

3 UN High Commissioner for Refugees. Two Million Syrians are Refugees. Press Statement, 3 set. 2013. Disponível em: < http://www.unhcr.org/522484fc9.html > Acesso em: dez. 2013. 
Além da questão síria, os relatos sobre crise separatista no $\mathrm{Mali}^{4}$, a instabilidade na Colômbia ${ }^{5}$ e os conflitos na República Democrática do Congo ${ }^{6}$, todos dão destaque às necessidades de proteção e de assistência humanitária trazidas à tona pela situação das pessoas forçosamente deslocadas que permanecem dentro das fronteiras de seus países. Essas evidências reforçam o argumento que atualmente é impossível se ter uma conversa sobre conflito armado ou ação humanitária sem considerar a situação dos deslocados internos (WEISS; KORN 2006, p. 9).

Estima-se que, atualmente, existam cerca de 33.3 milhões de pessoas deslocadas internamente, em razão de conflitos armados, violência generalizada e violações sistemáticas de direitos hu- manos $^{7}$. Trata-se do maior contingente de deslocados internos já registrado e que excede, de forma significativa, a estimativa de 18 milhões de refugiados atualmente em busca de proteção internacional $^{8 .}$

A maior parte do deslocamento intra-fronteiriço ocorre no continente africano, especialmente na África Subsaariana, onde 12.5 milhões de pessoas encontram-se em situação de vulnerabilidade. Igualmente impactante são os 9.1 milhões de deslocados internos presentes no Oriente Médio e Norte da África, em sua maioria dentro das fronteiras da Síria, país com o maior contingente de deslocados internos no mundo. A tabela abaixo apresenta dados sobre a distribuição geográfica atual da população deslocada.

4 THE GUARDIAN. Mali: a humanitarian snapshot of refugees, health and education. 15 maio 2013. Disponível em: <http://www.theguardian.com/global-development/picture/2013/may/15/mali-humanitarian-refugees-health-education>. Acesso em: dez. 2013. 5 THE GUARDIAN. Colombia's Internally Displaced People Caught in the Corridor of Instability. 12 ago. 2013. Disponível em: <http:/www.theguardian.com/global-development/2013/aug/12/colombia-internally-displaced-people-instability>. Acesso em: dez. 2013.

6 DR CONGO. UN Agency in of funding to assist growing number of displaced persons. 8 out. 2013. Disponível em: $<$ http://www.un.org/apps/news/story.asp/html/story.asp?NewsID $=46219 \& C r=$ democratic\&Cr1=congo\#.Up8QxxaYRAQ $>$. Acesso em: dez. 2013.

7 INTERNAL DISPLACEMENT MONITORING CENTRE. Global Overview 2013. Disponível em: $<$ http://www.internal-displacement.org/assets/publications/2014/201405global-overview-2014-en.pdf $>$. Acesso em: jul. 2014.

8 UNITED NATIONS HIGH COMMISSIONER FOR REFUGEE. World Refugee Day: global forced displacement tops 50 million for the first time in post-World War II era. Disponível em: <http://www.unhcr.org/53a155bc6.html>. Acesso em: jul. 2014. 


\section{Tabela 1 - Número de deslocados internos, por região e país de maior concentração (milhões)}

\begin{tabular}{|l|c|l|c|}
\hline \multicolumn{2}{|c|}{ Região } & \multicolumn{2}{c|}{ País } \\
\hline África Subsaariana & 12.5 & Síria & 6.5 \\
\hline $\begin{array}{l}\text { Oriente Médio e Norte da } \\
\text { África }\end{array}$ & 9.1 & Colômbia & 5.7 \\
\hline América & 6.3 & Nigéria & 3.3 \\
\hline Sul e Sudeste da Ásia & 3.2 & $\begin{array}{l}\text { República Democrática } \\
\text { do Congo }\end{array}$ & 2.9 \\
\hline Europa e Ásia Central & 2.2 & Sudão & 2.4 \\
\hline
\end{tabular}

Fonte: Internal Displacement Monitoring Centre (2014).

Deslocados internos dispõem de marco normativo próprio na seara internacional. Além dos Princípio Orientadores para os Deslocados Internos, instrumento declaratório endossado pelos principais organismos globais e regionais, dois tratados internacionais da região africana, um da União Africana e outro da sub-região dos Grandes Lagos, tratam especificamente do tema e dão-lhe força cogente 9 .

No campo operacional, o ACNUR atua em 20 países, incluindo aqueles com as maiores populações de deslocados internos ${ }^{10}$, para lhes prover proteção e abrigo emergencial. Apesar de ter um mandato legal específico para a proteção refugiados, o ACNUR vem assumido de facto o papel de principal agência humanitária responsável pela ajuda internacional aos deslocados internos (ORCHARD 2010).

Esse cenário de grande reconhecimento da situação deslocados internos e extensa atuação internacional, até pouco tempo atrás, no entanto, não existia. Antes do final dos anos 80, a expressão “deslocados internos" não era utilizada e as populações deslocadas internamente eram reconhecidas pelas organizações internacionais apenas quando vistas como refugiados em potencial. $\mathrm{O}$ foco da ação humanitária internacional era essencialmente centrado naqueles migrantes forçados que cruzavam as fronteiras de seus países (WEISS 2005).

9 Protocolo para a Proteção de Deslocados Internos da Região dos Grandes Lagos, que entrou em vigor em junho de 2008 após ratificação dos 11 países da região, e a Convenção da União Africana para Proteção e Assistência aos Deslocados Internos, que entrou em vigor em dezembro de 2012 após ratificação de 17 países africanos.

10 Afeganistão, República Centro-Africana, Chade, Colômbia, Costa do Marfim, República Democrática do Congo, Etiópia, Guiné, Nepal, Mali, Mianmar, Paquistão, Filipinas, Somália, Sri Lanka, Sudão, Sudão do Sul, Uganda, Iêmen e Zimbábue. 
A recente origem da proteção dos deslocados internos traz questionamentos sobre a própria estrutura da sociedade internacional. A criação da categoria de pessoas deslocadas internamente e a expansão do locus de atuação internacional para dentro das fronteiras não foram resultados inevitáveis de uma guerra sistêmica ou da obsolescência das regras de respeito à integridade territorial e de não-intervenção na jurisdição interna dos estados. Resultaram, ao contrário, de uma decisão gestada na seara internacional, impulsionada por seus atores e progressivamente acomodada em sua estrutura.

O presente artigo pretende explorar a evolução conceitual que resultou na criação dos deslocados internos como uma categoria internacional de proteção. De início, apresentará quem são os deslocados internos, situando temporalmente a evolução de sua definição e o desenvolvimento das modalidades internacionais de proteção. Por meio da evolução conceitual, demonstrarse-á como a definição se consolidou, na medida em que foi se distanciando na noção de deslocados internos como "refugiados em potencial". Em seguida, o texto argumentará que os deslocados internos são uma categoria típica da sociedade internacional de estados e que só poderia ser gestada em sua estrutura. Para tanto, conceitos de Direito Internacional serão aliados a uma matriz teórica de Relações Internacionais.

\section{QUEM SÃO OS DESLOCADOS INTERNOS?}

A definição de deslocados internos evoluiu de um completo vazio conceitual nos anos 70 para uma categoria sólida nos anos 90, definida com base em direitos humanos e responsabilidades nacionais e internacionais. A evolução dessa conceituação é apresentada a partir de quatro marcos temporais: (i) de 1972 a 1988, quando a menção a pessoas deslocadas internamente se restringia a potenciais fluxos de refugiados; (ii) de 1988 a 1992, com o surgimento das primeiras definições operacionais no contexto de inciativas de reconstrução pós-conflito; (iii) de 1992 a 1998, período em que se tomou a decisão de criar uma definição normativa de deslocados internos como categoria internacional; e (iv) de 1998 até os dias atuais, quando há o processo de consolidação da definição jurídica de deslocados internos e da norma internacional de proteção.

\section{2-1988: "Pessoas deslocadas" como refugiados em potencial}

As primeiras menções aos deslocados internos como grupo internacionalmente relevante foram feitas pela própria estrutura das Nações Unidas no início dos anos 70 (FELLER, 2006). Na época, no entanto, entendia-se que populações deslocadas internamente eram nada além 
de refugiados em potencial, que todavia não haviam cruzado uma fronteira internacional. $\mathrm{O}$ termo utilizado pela organização era "pessoas deslocadas", sem que houvesse qualquer delimitação de sua diferença em relação aos refugiados.

Esse entendimento foi utilizado primeiramente em 1972, quando a Assembleia Geral designou o ACNUR para coordenar os trabalhos de assistência humanitária no Sudão após conflito interno que forçou 180 mil refugiados a deixarem o país e outras 500 mil pessoas a se deslocarem para a região sul ${ }^{11}$. Em resolução intitulada Assistência a refugiados sudaneses retornando do exterior $^{12}$, a Assembleia Geral congratulou o ACNUR pela assistência e reassentamento de "refugiados e outras pessoas deslocadas" e solicitou a organização a seguir com esse trabalho.
Desde então, as demais resoluções referentes a essa operação passaram a intitular-se Assistência a refugiados e pessoas deslocadas no sul do Sudão ${ }^{13}$, o que acabou por consolidar o uso do termo "pessoas deslocadas" nos casos em que o ACNUR envolveu-se em situações similares. Por ser uma agência mandatada unicamente para a proteção e assistência a refugiados, o envolvimento do ACNUR com populações deslocadas internamente dependia de solicitação expressa da Assembleia Geral e circunscrevia-se a contextos de promoção de soluções duráveis ao problema dos refugiados ${ }^{14}$.

A assistência do ACNUR em favor de pessoas deslocadas foi solicitada no contexto outras situações de conflito, dentre as quais destacam-se os casos de Indochina (1975) ${ }^{15}$, Etiópia

11 UNITED NATIONS HIGH COMISSIONER FOR REFUGEES. UNHCR's Operations Experience with Internally Displaced Persons. Set. 1994. Disponível em: <http://www. refworld.org/docid/3ae6b3400.html>. Acesso em: dez. 2013.

12 UN GENERAL ASSEMBLY. Assistance to Sudanese refugees returning from abroad. 12 dez. . 1972, A/RES/2958. Disponível em: <http://www.refworld.org/docid/3b00f1b634. html>. Acesso em: dez. 2013.

13 UN ECONOMIC AND SOCIAL CONCIL (ECOSOC). Assistance to Southern Sudanese Refugees and Displaced Persons. 4 maio 1973, E/RES/1741 (LIV).

14 UNITED NATIONS HIGH COMISSIONER FOR REFUGEES. UNHCR's Operations Experience with Internally Displaced Persons. set. 1994. Disponível em: <http://www. refworld.org/docid/3ae6b3400.html>. Acesso em: dez. 2013.

15 UN GENERAL ASSEMBLY. Humanitarian Assistance to Indo-Chinese Displaced Persons. 9 dez. 1975, A/RES/3455 (XXX). 
$(1981)^{16}$, Chade (1984) ${ }^{17}$ e América Central (1987) ${ }^{18}$. Nesses casos, o envolvimento da agência deu-se em meio a programas de repatriação voluntária de refugiados, em que o movimento de retorno e os programas de reintegração incluíam ações voltadas aos dois grupos. Considerava-se pouco razoável tratar refugiados e deslocados de forma diferenciada no contexto de retorno e de reintegração às regiões de origem ${ }^{19}$.

Ademais dos pedidos de assistência feitos ao ACNUR, outros órgãos da ONU também passaram a utilizar o termo "pessoas deslocadas" na acepção de indivíduos em situações similares às dos refugiados (refugee-like situations). Esse é o caso dos primeiros estudos realizados pela organização, nos anos 80 , sobre iniciativas de prevenção de fluxos massivos de refugiados.
Em seu famoso relatório sobre Direitos Humanos e Exodos Massivos, Sadrudin Aga Khan, que foi Alto Comissário das Nações Unidas para Refugiados entre 1966 e 1978, fala em "fluxos massivos de refugiados e pessoas deslocadas" de forma conjunta, assumindo o não-atravessamento de fronteiras como circunstancial, já que ambos os grupos partilham do mesmo tipo de migração forçada. Da mesma forma, o Grupo de Especialistas Governamentais sobre Cooperação Internacional para Prevenir Fluxos de Refugiado ${ }^{20}$ assume, em seu relatório, que pessoas deslocadas são potenciais refugiados e que devem consideradas quando do desenvolvimento de ações de prevenção as fluxo massivos através das fronteiras.

16 UN GENERAL ASSEMBLY. Assistance to displaced persons in Ethiopia. 17 dez. 1982, A/RES/37/175. Disponível em: <http:/www.refworld.org/docid/3b00f0199.html>. Acesso em: dez. 2013.

17 UN GENERAL ASSEMBLY. Emergency assistance to returnees and displaced persons in Chad. 14 dez. 1984, A/RES/39/106. Disponível em: <http://www.refworld. org/docid/3b00f00e30.html>. Acesso em: dez. 2013.

18 UN GENERAL ASSEMBLY. Assistance to refugees, returnees and displaced persons of Central America, 7 dez. 1987, A/RES/42/110. Disponível em: <http://www.refworld. org/docid/3b00effc2c.html>. Acesso em: dez. 2013.

19 UNITED NATIONS HIGH COMISSIONER FOR REFUGEES. Op. Cit. nota. 12. 20 UN GENERAL ASSEMBLY. International Co-operation to Avert New Flows of Refugees: Note by the Secretary-General. 13 maio 1986, A/41/324. Disponível em: <http:// www.refworld.org/docid/3ae68bee4.html>. Acesso em: dez. 2013. 


\section{8-1992: "Deslocados internos" e as primeiras definições operacionais}

A partir de 1988, nota-se uma inflexão na terminologia referente às pessoas deslocadas, assim como um aprofundamento nas discussões sobre sua condição. As agências humanitárias e ONGs internacionais, cada vez mais envolvidas em situações de reconstrução pós-conflito, passam a reconhecer duas principais diferenças dos deslocados em relação aos refugiados: os primeiros são mais numerosos e menos amparados internacionalmente. Com base nesse reconhecimento, "pessoas deslocadas" tornam-se "deslocados internos", um grupo diferenciado que, ao contrário dos refugiados, não dispõe de arranjo institucional específico para sua proteção.

O marco de 1988 é creditado à Conferência Internacional sobre Refugiados, Retornados e Pessoas Deslocadas no Sul da África (SARRED), realizada em Oslo em agosto daquele ano. Trata-se de iniciativa organizada pela Organização da Unidade Africana (atual União Africana) e apoiada pela ONU, com o objetivo de chamar a atenção para a situação de deslocamento forçado nos países da região ${ }^{21}$ e estimular inciativas de cooperação internacional, assistência humanitária e desenvolvimento para a resolução da crise. ${ }^{22}$

Em seu discurso durante a Conferência, o então Alto Comissário das Nações Unidas para os Refugiados, Jean-Pierre Hocké, enfatizou a diferença entre deslocados internos e refugiados em termos de magnitude. Enquanto os países da região abrigavam mais de 1 milhão de refugiados, permaneciam dentro das fronteiras 5 milhões de deslocados internos ${ }^{23}$.

A ausência de um órgão operacional mandatado especificamente para prover assistência aos deslocados internos também foi destacada, uma vez que a implementação de projetos de desenvolvimento nos países da região dependia iniciativas em favor dessas populações. Nesse sentido, a Declaração e o Plano de Ação de Oslo, documentos finais da Conferência, contém solicitação explícita ao Secretário-Geral da ONU para "realizar estudos e consultas para assegurar modalidades de implementa-

21 Angola, Botswana, Lesoto, Malaui, Moçambique, Suazilândia, Tanzânia, Zâmbia e Zimbábue.

22 UN GENERAL ASSEMBLY. International Conference on the Plight of Refugees, Returnees and Displaced Persons in Southern Africa (SARRED): Report of the Secretary-General. 19 out.1988, A/43/717. Disponível em: <http://www.refworld.org/ docid/3ae68f410.html>. Acesso em: dez. 2013.

23 Ibid. 
ção e de coordenação de programas de assistência para deslocados internos ${ }^{24}$ ".

Além da SARRED, outra conferência regional que contribuiu para destacar a necessidade de proteção internacional para deslocados internos foi a Conferência Internacional sobre os Refugiados da América Central (CIREFCA), realizada em na cidade da Guatemala em maio de 1989. O propósito da Conferência era achar soluções duráveis para o deslocamento massivo na região, com foco no retorno e na reintegração de refugiados, aplicando uma abordagem que associasse assistência e desenvolvimento (BETTS, 2006).

Assim como na SARRED, o ethos desenvolvimentista da CIREFCA, que buscava a reintegração das populações deslocadas e o fortalecimento das comunidades locais, enfatizou a necessidade de se lidar com a situação dos deslocados internos, que estavam fora do mandato de proteção e de assistência do ACNUR. O Plano de Ação da Conferência, além de reconhecer o maior número de deslocados internos na região em relação aos refugiados ${ }^{25}$, reforça o argumento de que o grupo merece assistência internacional não obstante estar dentro das fronteiras e sob a jurisdição de seu país de residência.

6. O conflito e a crise provocaram igualmente o deslocamento de um terceiro grupo muito importante de pessoas que permaneceram dentro de seu próprio país sem lar e sem meios de subsistência. Esses se denominam deslocados internos e, ainda que se encontrem sujeitos à jurisdição e à proteção das autoridades de seus próprios países, requerem também assistência internacional (tradução e grifo nossos) ${ }^{26}$.

A importância dessas duas conferências regionais para a evolução da definição de deslocados internos é notável (COHEN; DENG, 2008, p. 5). Segundo Beyani, as fronteiras de proteção se expandiram no final dos anos $80 \mathrm{com}$ a integração entre assistência e desenvolvimento e com a inclusão dos deslocados internos no vocabulário da proteção internacional, anteriormente centrado nos refugiados (BEYANI, 2013, p. 12).

Em resposta às provocações das conferências regionais acerca da au-

24 UN GENERAL ASSEMBLY. International Conference on the Plight of Refugees, Returnees and Displaced Persons in Southern Africa: resolution / adopted by the General Assembly. 8 dec. 1988, A/RES/43/116. Disponível em: <http://www.refworld.org/ docid/3b00eff694.html>. Acesso em: dez. 2013.

25 CIREFCA. Declaration and Concerted Plan of Action in Favour of Central American Refugees, Returnees and Displaced Persons. 30 de maio de 1989, CIREFCA 89/13/ Rev.1, parágrafo 28. Disponível em: <http://www.refworld.org/docid/3fbb5d094.html $>$. Acesso em: dez. 2013.

26 Ibid, parágrafo 6 . 
sência de um órgão mandatado para lidar com deslocados internos ${ }^{27}$, o Secretário-Geral da ONU, Javier Pérez de Cuellar, publica o primeiro relatório da organização sobre o tema. A tentativa inicial de construir uma definição para o grupo resultou na seguinte formulação.

Para os propósitos do presente relatório, deslocados internos são consideradas pessoas que foram forçadas a abandonar seus lares ou suas atividades econômicas regulares, permanecendo dentro dos seus países de origem, porque suas vidas, segurança ou liberdade foram ameaçadas por violência generalizada, conflitos armados, distúrbios internos ou eventos similares que perturbem a ordem pública: (tradução nossa) ${ }^{28}$

Trata-se de uma definição instrumental, limitada ao escopo do relatório. Seu maior propósito foi destacar a principal diferença entre deslocados internos e refugiados, i.e. a permanência dos primeiros dentro de seu país. Utiliza-se até a expressão "país de origem", típica do direito internacional dos refugiados, para se referir ao país de residência do deslocado interno e, portanto, traçar uma comparação direta entre das duas categorias.

Pode-se afirmar que a definição está centrada nessa diferenciação entre as categorias porque esse é o único aspecto discutido ao longo do relatório. A definição até busca elencar algumas causas do deslocamento interno (i.e. violência generalizada, conflitos armados, distúrbios internos ou eventos similares que perturbem a ordem pública), mas não explica o porquê dessas escolhas.

No relatório, o Secretário-Geral afirma que os deslocados internos são de responsabilidade primária dos governos nacionais dado que permanecem no território de seus países. Isso justificaria a ausência de um corpo normativo e de um arranjo institucional específico para o grupo, como há para os refugiados. Javier Pérez de Cuellar posicionou-se, portanto, contrariamente a um mandato humanitário específico para deslocados internos, mas delegou aos Representantes Residentes do Programa das Nações Unidas para o Desenvolvimento (PNUD), em cada país, a função de ponto focal in loco para o tema ${ }^{29}$.

27 UN GENERAL ASSEMBLY. International Conference on the Plight of Refugees, Returnees and Displaced Persons in Southern Africa : resolution / adopted by the General Assembly. 8 dez. 1988, A/RES/43/116, Disponível em: <http://www.refworld.org/ docid/3b00eff694.html>. Acesso em: dez. 2013.

28 UN GENERAL ASSEMBLY. International Conference on the Plight of Refugees, Returnees and Displaced Persons in Southern Africa: Report of the Secretary-General. 28 set. 1989, A/44/520, parágrafo 72 .

29 Ibid., parágrafo 80 . 
Essa delegação de competência manteve a pauta viva nas Nações Unidas e levou o PNUD a solicitar esclarecimentos ao Secretário-Geral acerca da experiência e da capacidade das organizações do sistema ONU para assistir deslocados internos em suas necessidades e para apoiar os estados nacionais a lidar com o problema ${ }^{30}$.

Em novo relatório, preparado pelo especialista Jacques Cuenod e submetido ao Secretário-Geral, deslocados internos foram novamente definidos vis$-\grave{a}$-vis os refugiados, sendo os primeiros aqueles que "permanecem dentro das fronteiras de seus países ${ }^{31}$ " enquanto os últimos as atravessam. Cuenod chega a criticar a primeira tentativa de definição do Secretário-Geral, considerando muito restritivas as causas enumeradas de deslocamento interno. Segundo ele, além de violações generalizadas de direitos humanos, desastres naturais e provocados pelo homem também causam movimentos massivos e devem constar de uma definição mais abrangente.

Mesmo com esse novo relatório, não se tinha, ao final de 1991, uma definição formal de deslocados internos. O que se consolidou, no entanto, foram aos seguintes pontos: (i) o termo "deslocados internos" substituindo "pessoas deslocadas"; (ii) a diferença espacial deles em relação aos refugiados; (iii) a diferença numérica entre os dois grupos; (iv) a necessidade de inclusão dos deslocados internos em esforços de reconstrução pós-conflito e desenvolvimento; e (v) o questionamento sobre a ausência de um arranjo internacional específico para lhes dar assistência e proteção.

Esses fatores permitiram que o assunto evoluísse até que a Comissão de Direitos Humanos da ONU aprovasse sua primeira resolução com o título "deslocados internos" em 1991 ${ }^{32}$. Essa resolução instituiu o tema como pauta internacional permanente, assim como deu-lhe linguagem própria de direitos humanos.

30 UN ECONOMIC AND SOCIAL COUNCIL (ECOSOC). UN Economic and Social Council Resolution 1990/78: Refugees, displaced persons and returnees. 27 jul. 1990, E/RES/1990/78. Disponível em: <http://www.refworld.org/docid/3ae69eed24.html>. Acesso em: dez. 2013.

31 UN ECONOMIC AND SOCIAL COUNCIL (ECOSOC). Note / by the SecretaryGeneral pursuant to Economic and Social Council resolution 1990/78: addendum; report on refugees, displaced persons and returnees, prepared by Mr. Jacques Cuénod, Consultant. 27 jun. 1991, E/1991/109/Add.1. Disponível em: <http://www.refworld.org/ docid/49997afe4.html>. Acesso em: dez. 2013.

32 UN COMMISSION ON HUMAN RIGHTS. Internally displaced persons. 5 março 1991, E/CN.4/RES/1991/25. Disponível em: <http://www.refworld.org/docid/3b00f0b1c. html>. Acesso em: dez. 2013. 
1992-1998: Construção da definição normativa e das modalidades de envolvimento internacional

O período de 1992 a 1998 foi o mais importante no que tange à afirmação dos deslocados internos como categoria internacional própria e delimitada. Nesses seis anos, as tentativas de definir o grupo apenas em comparação com os refugiados foram superadas. A definição de deslocados internos, assim como seus direitos e as responsabilidades internacionais a eles associadas, passaram a ser entendidos como função do reconhecimento das vulnerabilidades específicas e das necessidades especiais de proteção do grupo.

Em resposta à resolução da Comissão de Direitos Humanos, o novo Secretário-Geral, Boutros Boutros-Ghali, preparou relatório sobre a situação dos deslocados internos, enfatizando as dimensões de direitos humanos do problema ${ }^{33}$. O relatório inicia estabelecendo a magnitude internacional do deslocamento interno que, em 1992, afetava aproximadamente 24 milhões de pessoas. Esse número foi comparado ao dos 17 milhões de refugiados, mas, dada a grandeza do problema dos deslocados internos e sua abrangência global, essa comparação foi deixando de ser reafirmada.

Posteriormente, o texto apresenta a primeira definição normativa de deslocados internos, que orientou os trabalhos e debates até a decisão de se criar um instrumento internacional. Deslocados internos, nesse entendimento, seriam:

Pessoas, ou grupos de pessoas que foram forçados a fugir de suas casas, de forma repentina ou inesperada, em grandes números, como resultado de conflito armado, lutas internas, violações sistemáticas de direitos humanos ou calamidades naturais ou humanas, e que permanecem dentro do território seu país ${ }^{34}$.

Essa definição reafirma e desenvolve três elementos centrais: a permanência dos indivíduos dentro do país; o caráter coercitivo e involuntário do deslocamento; e suas principais causas. Nota-se que, em relação à primeira definição operacional, a expressão "país de origem" foi substituída por "território de seu país" e foram incorporadas formulações mais abrangentes para as causas do deslocamento.

O teor dessa definição seguiu sendo discutido na ONU, mas com um importante qualificador: em 1992, a Comissão de Direitos Humanos pediu ao Secretário-Geral que designasse um

33 UN COMMISSION ON HUMAN RIGHTS. Analytical Report of the Secretary-General on Internally Displaced Persons. 14 fev. 1991, E/CN.4/1992/23.

34 Ibid., parágrafo 17. 
Representante para Deslocados Internos para examinar situações concretas de deslocamento interno e apontar leis e normas internacionais aplicáveis à proteção e à assistência ao grupo ${ }^{35}$. O posto foi assumido pelo diplomata sudanês Francis Deng pelo período de 1992 a 2004. Seu trabalho centrou-se em três vertentes: visitas a países afetados pelo deslocamento interno; promoção de um arranjo institucional que atuasse em favor do grupo; e desenvolvimento de um marco normativo que respondesse às necessidades de proteção e de assistência aos deslocados internos (COHEN; DENG, 1998).

Com base em evidências coletadas nas visitas do Representante ${ }^{36}$, identificaram-se alguns problemas com a definição proposta em 1992. A formulação falava em pessoas forçadas a "fugir", "de forma repentina ou inesperada" e em "em grandes números". A realidade, no entanto, mostrou que nem todos os deslocados fugiam de forma repentina, mas poderiam ser forçados a abandonar suas casas mediante resistência, como ocorria nos casos de limpeza étnica nos Bálcãs ou enfrentamentos com guerrilhas na Colômbia (PHUONG 2004).
O caso colombiano também demonstrou que o deslocamento poderia ocorrer em pequenos grupos, exatamente para chamar menos a atenção dos agentes perseguidores. A expressão "em grandes números", típica do foco histórico dado a êxodos em massa, limitava o escopo da definição.

Essas deficiências foram corrigidas em 1998, quando os Princípios Orientadores para os Deslocados Internos foram apresentados à ONU como um novo marco normativo da categoria. Baseados em tratados de direitos humanos, direito humanitário e direito dos refugiados (por analogia), os Princípios tinham o objetivo de promover os direitos dos deslocados internos e de definir as responsabilidades dos estados e da comunidade internacional para sua proteção e assistência.

Segundo os Princípios, deslocados internos são definidos como:

Pessoas, ou grupos de pessoas, forçadas ou obrigadas a fugir ou abandonar suas casas ou seus locais de residência habituais, particularmente em consequência de, ou com vistas a evitar os efeitos dos conflitos armados, situações de violência generalizada, violações de direitos humanos ou calamidades humanas ou

35 UN COMMISSION ON HUMAN RIGHTS. Internally displaced persons. 5 mar. 1992, E/CN.4/RES/1992/73. Disponível em: <http://www.refworld.org/docid/3b00f0e71c. html>. Acesso em: dez. 2013.

36 Entre 1992 e 1998, o Representante visitou os seguintes países: ex-Iugoslávia, Rússia, Sudão, Somália e El Salvador (1992); Sri Lanka (1993); Colômbia, Burundi e Ruanda (1994); Peru (1995); Tajiquistão e Moçambique (1996); e Azerbaijão (1998). 
naturais, e que não tenham atravessado uma fronteira internacionalmente reconhecida de um Estado ${ }^{37}$.

Além de responder às deficiências identificadas previamente, essa definição apresenta duas inovações. Em primeiro lugar, o termo particularmente é incluído para evitar que a enumeração das causas do deslocamento tenha um caráter excludente. Novas categorias de deslocados internos, não identificadas no momento em que os Princípios foram elaborados, poderão ser incluídas na definição (KALIN, 2008).

Em segundo lugar, a expressão "que permanecem dentro do território seu país" é substituída por "que não tenham atravessado uma fronteira internacionalmente reconhecida de um Estado". Essa mudança suprime a inferência de que deve haver algum vínculo entre o país e o deslocado interno, como nacionalidade ou cidadania, e coloca a fronteira como única referência espacial. $\mathrm{O}$ reconhecimento de um indivíduo como deslocado interno está, portanto, atrelado ao não cruzamento da fronteira internacional.

Tanto a definição como toda a estrutura dos Princípios Orientadores foram construídos com base na premissa de que os deslocados internos possuem ne- cessidades específicas que justificam sua delimitação como categoria, não podendo ser considerados apenas refugiados em potencial (KALIN, 1998). Em razão de seu deslocamento, por exemplo, os deslocados internos são alijados de suas comunidades e, além de ficarem sem abrigo, alimentação e meios de sobrevivência, não dispõem de acesso à assistência internacional. Sofrem discriminação e violência nas localidades vizinhas onde tentam se estabelecer. Perdem, em muitas situações, a propriedade das residências que tiveram de abandonar e para onde desejam retornar. Constituem-se principalmente de crianças e de mulheres, que são vulneráveis a tipos específicos de violência. Em suma, os deslocados internos sofrem os efeitos da crise que provocou seu movimento antes, durante e depois do deslocamento e, portanto, apresentam vulnerabilidades específicas que passaram a ser reconhecidas e consideradas na sua própria definição, assim como em seus direitos e nas responsabilidades a eles associadas (MOONEY, 2005).

Para responder às necessidades específicas do grupo, os Princípios foram organizados de acordo com as diferentes fases do deslocamento: proteção contra o deslocamento forçado; proteção e

37 UN COMMISSION ON HUMAN RIGHTS. Report of the Representative of the Secretary-General on Internally Displaced Persons: Guiding Principles on Internal Displacement. 11 fev. 1998, E/CN.4/1998/53/Add.2. Disponível em: <http://www. refworld.org/docid/3d4f95e11.html>. Acesso em: dez. 2013. 
assistência durante o deslocamento; e proteção durante o retorno e o reassentamento. A base legal do instrumento está na complementaridade entre Direto Internacional dos Direitos Humanos, Direito Internacional Humanitário e Direito Internacional dos Refugiados, sendo que as garantias presentes nesses ramos do direito são reiteradas no caput cada princípio e são posteriormente complementadas por formulações jurídicas especificamente aplicáveis aos deslocados internos. Algumas dessas formulações trazem inovações conceituais que estavam ausentes dos instrumentos legais já existentes, como e.g. o direito a não ser arbitrariamente deslocado; garantias especiais a mulheres e crianças deslocadas; proibição ao retorno forçado a áreas perigosas; e princípios sobre os direitos de restituição de propriedade a populações deslocadas.

Esses avanços normativos também impulsionaram respostas institucionais. Apesar de seguir sem uma organização própria, os deslocados internos passaram contar com reforço na coordenação entre as diferentes agências humanitárias. Ao mesmo tempo em que reconhece a primazia dos estados em lidar com os deslocados internos, a ONU institui uma "abordagem colaborativa" entre agências humanitárias internacionais. Nesse arranjo, o Coordenador do Comitê Interagencial da ONU, foro que reúne diversas agências de mandato humanitário, interage com os diversos Representantes Residentes do PNUD para traçar estratégias específicas de assistência e proteção aos deslocados internos que incluam a participação de governos nacionais, agências da ONU, organizações internacionais e ONGs (DENG; MACNAMARA, 2001).

\section{8: Consolidação da definição jurídica e da norma internacional de proteção}

Os Princípios Orientadores, após serem apresentados à Comissão de Direitos Humanos, passaram a ser endossados por organizações regionais, agências especializadas, cortes internacionais e outros mecanismos de monitoramento de direitos humanos. Em 2005, o ex-Secretário-Geral da ONU, Kofi Annan, referiu-se aos Princípios como "norma internacional básica" de proteção dos deslocados internos ${ }^{38}$, posição posteriormente referendada pelo Documento Final da Cúpula Mundial do mesmo nno $^{39}$.

38 UN GENERAL ASSEMBLY. In Larger Freedom: towards development, security and human rights for all: Report of the Secretary-General. 21 mar. 2005, A/59/2005. Disponível em: <http://www.refworld.org/docid/4a54bbfa0.html>. Acesso em: dez. 2013.

39 UN GENERALASSEMBLY. 2005 World Summit Outcome: Resolution adopted by the 
A definição de deslocados internos presente nos Princípios Orientadores, assim como os direitos enunciados no documento, serviram como base para dois tratados internacionais, com efeito vinculante, da região africana, i.e. Protocolo para a Proteção de Deslocados Internos da Região dos Grandes Lagos (2008) e a Convenção da União Africana para Proteção e Assistência aos Deslocados Internos (2009). O primeiro, resultado do processo de paz da sub-região dos Grandes Lagos, foi ratificado pelos 11 países envolvidos e busca oferecer resposta humanitária a um dos maiores contingentes de deslocados internos do mundo. O Protocolo dos Grandes Lagos, além de dar força cogente aos Princípios e vincular os estados a incorporarem-nos nas legislações nacionais, dá um passo além e torna-se o primeiro tratado que explicitamente estabelece uma obrigação internacional de proteção e de assistência humanitária aos deslocados internos (NOGUEIRA, 2012), conforme disposto em seu artigo 10 :

10. Quando os Governos dos Estados Membros não dispuserem de capacidade para proteger e assistir os deslocados internos, esses Governos deverão aceitar e respeitar a obrigação dos órgãos da comunidade internacional de prover proteção e assistência aos deslocados internos (tradução e grifo nossos).

Já a Convenção da União Africana, também conhecida como Convenção de Kampala, também avança em relação aos Princípios. Ao passo em que incorpora a mesma definição de deslocados internos, define e expande o alcance do "direito a não ser deslocado arbitrariamente", incluindo a proibição contra novas causas de deslocamento, como discriminação, conflito armado, violência generalizada e violações de direitos humanos, práticas danosas, evacuações desnecessárias e punições coletivas (BRADLEY; ASPLET 2012). Ademais, a Convenção vincula os estados não apenas a assistir aos deslocados e a compensá-los por suas perdas, mas também devem se comprometer a reconhecer e a respeitar o papel das organizações humanitárias internacionais na proteção dos deslocados internos, assim como o direito dessas organizações de oferecer assistência humanitária.

No continente americano, a menção às vulnerabilidades específicas dos deslocados internos estão presentes em dois tratados da região, i.e. Convenção Interamericana para Prevenir, Punir e Erradicar a Violência contra a Mulher (1994) e Convenção Interamericana contra Toda Forma de Discriminação e Intolerância (2013). Além disso, a Corte Interameri-

General Assembly. 24 out. 2005, A/RES/60/1. Disponível em: <http://www.refworld. org/docid/44168a910.html>. Acesso em: dez. 2013. 
cana de Direitos firmou jurisprudência regional em que reconhece as vulnerabilidades específicas dos deslocados internos como categoria, interpreta-as de acordo com obrigações internacionais de direitos humanos e vincula os estados a facilitar seu retorno voluntário e a restituição de sua propriedade (NOGUEIRA; EFSTATHOPOULOS, 2007).

No plano doméstico, 25 países, dentre eles Angola, Burundi, Libéria, Uganda, Índia, Iraque, Sri Lanka, Azerbaijão, Bósnia, Geórgia, Rússia, Sérvia, Turquia, Colômbia e Peru, já possuem legislações nacionais sobre deslocados internos, inspiradas nos Princípios Orientadores ${ }^{40}$. Um dos maiores benefícios dessas leis foi estender aos próprios deslocados internos a posse de um status que apenas lhes era reconhecido internacionalmente e, portanto, difícil de ser traduzido em direitos ou benefícios. Na Colômbia, por exemplo, a legislação possibilitou aos desplazados se reconhecerem como grupo, organizarem-se politicamente e serem destinatários de políticas públicas específicas de renda e de moradia (MARTIN, 2005).

A estrutura internacional humanitária, por sua vez, reconheceu a necessidade de promover novo incremento em sua atuação em favor dos deslocados internos. Em 2005, no marco de uma reforma promovida por Kofi Annan, substituiu-se a "abordagem colaborativa" por uma "abordagem setorial" (cluster approach), em que as principais necessidades dos deslocados internos foram separadas em setores de atuação, delegados às agências especializadas consideradas mais experientes. O ACNUR é a instituição líder nas áreas de proteção, abrigo e administração de campos e progressivamente aumenta sua presença em um maior número de estados afetados por deslocamento interno. Os deslocados internos tornaramse, para o ACNUR, sua segunda maior "população de interesse" da agência, depois dos refugiados ${ }^{41}$.

\section{UMA CATEGORIA \\ DA SOCIEDADE INTERNACIONAL}

A evolução dos debates que resultaram na definição de deslocados internos demonstra que a categoria, assim como a norma que rege sua proteção, são produtos de articulações originadas exclusivamente na seara internacional.

40 Conferir. $<$ http://www.brookings.edu/about/projects/idp/resources/idp-policies-index $>$. Acesso em: dez. 2013.

41 UN HIGH COMMISSIONER FOR REFUGEES. State of the Worlds Refugees 2012: In Search of Solidarity, 2012. Disponível em: <http://www.unhcr.org/4fc5ceca9.html>. Acesso em: dez. 2013. 
Cabe, no entanto, ir além dessa constatação e argumentar que os deslocados internos são uma categoria típica da sociedade internacional e que só poderia ser gestada em sua estrutura.

São duas as características primordiais dos deslocados internos que seguem reiteradas desde o início dos debates sobre a definição: o deslocamento forçado e a permanência dentro das fronteiras. O deslocamento, como se viu, tem causas diversas e distintas, que vão de conflitos armados a desastres naturais, havendo ainda a possibilidade de se incluir novas causas, como o deslocamento provocado por projetos de desenvolvimento (CERNEA, 2006). O elemento, portanto, que dá unidade à categoria dos deslocados internos é o não cruzamento de fronteiras internacionais.

As fronteiras são elemento próprio da sociedade internacional. Ao delimitarem o espaço de jurisdição dos estados soberanos, as fronteiras tornamse objeto de reconhecimento mútuo e de legitimidade perante os membros da sociedade internacional. Segundo Williams, as fronteiras territoriais dos estados são as principais linhas que dividem e definem a sociedade internacional (WILLIAMS, 2011).

Teóricos como Robert Jackson e Barry Buzan entendem as fronteiras como uma instituição da sociedade internacional, ou seja, uma prática que estados fazem, de forma reiterada, para colaborarem entre si, com propósito de salvaguardar objetivos e interesses comuns relacionados à manutenção da ordem internacional (JACKSON, 2002; BUZAN, 2004). Nas palavras de Hedley Bull:

As instituições servem para simbolizar a existência de uma sociedade internacional que representa mais do que a soma dos seus participantes, para dar substância e permanência à colaboração dos estados no exercício das funções políticas da sociedade internacional e para moderar a sua tendência de perder de vista os interesses comuns (BULL, 2002, p. 89).

Nesse entendimento, as fronteiras, assim como as instituições clássicas de Bull (i.e. diplomacia, direito internacional, equilíbrio de poder, guerra e o papel das grandes potencias), dão efetividade às regras básicas de coexistência entre estados, como é o caso do respeito à jurisdição exclusiva (BULL, 2002). Além de materializar o elemento de territorialidade, essencial à conformação da sociedade internacional moderna, as fronteiras estabelecem os limites da jurisdição interna dos estados e caracterizam as ações de interferência indevida.

Fica claro, portanto, que as fronteiras internacionais, assim como as outras instituições, carregam grande força normativa, dotando os estados de determinadas obrigações e prerrogativas. Segundo Jackson, a obrigação de respeito às fronteiras está mais claramente expressa no artigo 2 da Carta das Nações 
Unidas, que trata da abstenção do uso da força contra a integridade territorial de um estado e da não-interferência em assuntos circunscritos à jurisdição interna de qualquer estado (JACKSON, 2002).

Importante notar que as obrigações derivadas e delimitadas pelas fronteiras, i.e. o respeito à integridade territorial $\mathrm{e}$ a não-intervenção na jurisdição interna, são obrigações negativas, que prescrevem aos membros da sociedade internacional um comportamento cauteloso em relação aos assuntos internos de cada estado. A menção ao não cruzamento de fronteiras na definição dos deslocados internos está intimamente ligada a essa cautela. Por mais numerosos e vulneráveis que sejam os deslocados internos, a sua circunscrição dentro das fronteiras limita as possibilidades de atuação internacional.

Isso ocorre porque os deslocados internos surgiram tendo os refugiados como parâmetro, que já dispunham de um robusto corpo normativo e institucional de proteção. Ao se demarcar, com clareza, a diferença de lugar entre as duas categorias em relação às fronteiras, demarcava-se também as diferenças de abordagem e de possibilidades de atuação internacional. Cabe explorar uma pouco mais essa diferença.

\section{Refugiados e Deslocados Internos}

Os refugiados também são uma categoria própria da sociedade internacional.
Assim como os deslocados internos, sua definição é vinculada aos elementos de fronteira e de territorialidade, constitutivos do sistema de estados moderno. Contudo, o surgimento dos refugiados como categoria, assim como a lógica que rege sua proteção internacional, têm origens bastante diferentes.

O movimento de pessoas entre entidades políticas distintas e os pedidos de asilo ou santuário são comuns ao longo da História. Os refugiados, no entanto, são produto da vinculação entre estado, nação e território, que se iniciou com a Paz de Vesfália no século XVII e consolidou-se no início do século XX. A divisão de todo o território em diferentes unidades políticas delimitadas cria a necessidade de se regular internacionalmente a situação daqueles que se situam "entre as fronteiras" (HADDAD, 2008).

Os primeiros arranjos normativos $\mathrm{e}$ institucionais de proteção aos refugiados surgiram no período entre guerras, quando a dissolução dos impérios como o Otomano e o Czarista deram lugar à uma organização do sistema de estados regida pela vinculação direta entre território e nação (BARKIN; CRONIN 1994). O esforço de desenhar fronteiras baseadas em nacionalidade e circunscrever populações etnicamente homogêneas a estados territoriais acabou por não encapsular todos os povos e excluir nacionalidades dessa nova lógica de sistemas de estados. Foi o que aconteceu com russos expulsos da revolução, ar- 
mênios excluídos da Turquia e judeus perseguidos por regimes fascistas, sendo esses os primeiros grupos a receberem passaportes especiais de refugiados ("passaportes Nansen") e auxílio da Liga das Nações para se integrarem em outro país (GOODWIN-GILL 1996; LOESCHER, 1996).

Após a Segunda Guerra Mundial, quando milhões de pessoas estavam fora de seus países de origem precisando de assistência, decidiu-se criar um definição legal de refugiado de alcance universal, positivada na Convenção de 1951, e dar mandato específico a uma organização internacional, o ACNUR, para lidar com o problema. O texto da Convenção, que define refugiados como aqueles que "em razão de fundado temor de perseguição por motivos de raça, religião, nacionalidade, grupo social ou opiniões políticas encontram-se fora de seu país de nacionalidade ou de residência habitual e a ele não podem retornar", levou em consideração a principal causa de deslocamento forçado da época - a perseguição - para construir um status legal diferenciado (GOODWIN-GILL, 1996).

Até a década de 1960, no entanto, acha-se que o fenômeno do refúgio era temporário e que cessaria com a fixação das fronteiras e o com soluções duráveis para as vítimas da guerra. Ficou claro, contudo, que enquanto se tentar atrelar todos os indivíduos a estados territoriais, haverá sempre falhas dos estados em protegê-los e isso resultará em movimentos transfronteiriços de refugiados. Com a expansão do sistema de estados para todo globo (WATSON, 2004), especialmente após os processos de descolonização, o refúgio, assim como o escopo do regime internacional de proteção dos refugiados, tornou-se universal (BETTS; LOESCHER, 2011).

Os constantes alargamentos na definição de refugiado são resultado da identificação de outras causas de movimentos transfronteiriços que vão além da perseguição individualizada. A Convenção de 1969 da Organização da Unidade Africana ${ }^{42}$ acrescenta "agressão, ocupação externa, dominação estrangeira ou a acontecimentos que perturbem gravemente a ordem pública" às causas do refúgio. A Declaração de Cartagena de $1984^{43}$, referendada pelos estados latino-americanos, sugere que devam ser reconhecidos como refugiados aqueles cuja "vida, segurança ou liberdade

42 Convenção da Organização da Unidade Africana que rege Aspectos Específicos dos Problemas dos Refugiados em África. Adotada pela Conferência dos Chefes de Estado e de Governo quando da Sexta Sessão Ordinária (Adis-Abeba, 10 de Setembro de 1969), tendo entrado em vigor em 20 de Junho de 1974.

43 A Declaração de Cartagena sobre Refugiados, de 1984, foi resultado dos encontros de representantes governamentais e especialistas de dez países latino-americanos em Cartagena de Indias, Colômbia, para considerar a situação dos refugiados na América Latina. 
tenham sido ameaçadas pela violência generalizada, a agressão estrangeira, os conflitos internos, a violação maciça dos direitos humanos ou outras circunstâncias que tenham perturbado gravemente a ordem pública." Essa expansão da definição de refugiados reforça a longevidade da categoria na sociedade internacional, assim como a legitimidade do envolvimento internacional para sua proteção.

Assim sendo, pode-se entender que a lógica da proteção internacional dos refugiados está calcada em dois pilares principais: o cruzamento forçado das fronteiras e a consequente quebra da relação "estado - cidadão - território" (HADDAD, 2008) que caracteriza a sociedade internacional.

Sobre a necessidade do cruzamento de fronteiras para a qualificação como refugiado e o consequente direito à proteção internacional, Haddad diz o seguinte:

Para se qualificar como refugiada, a pessoa deve ter cruzado uma fronteira internacional. Ao cruzar essa fronteira, ela se tornar uma preocupação internacional, criando problemas potenciais para outros estados e não apenas seu estado de origem. Movimentos massivos de refugiados são normalmente vistos como uma ameaça à ordem internacional em razão de seus efeitos desestabilizadores no sistema de estados. Assim, a refugiada transforma-se em um problema a ser colocado na agenda internacional para discussão e resolução (HADDAD, 2008). (tradução nossa)
Em uma sociedade internacional divida em estados soberanos, o cruzamento forçado de fronteiras resume, por excelência, a falha de proteção do estado em relação ao seu cidadão. Além disso, coloca o indivíduo necessariamente no alcance de atuação internacional, uma vez que esse refugiado deverá ser acolhido por outro estado soberano. Como diriam Loescher e Dowty, o movimento de pessoas por meio de fronteiras nacionais sob coação internacionaliza o que antes seriam assuntos puramente domésticos relacionados às causas do movimento (LOESCHER; DOWNTY, 1996).

Segundo entendimento proposto por Haddad, o refugiado é uma anomalia inevitável e permanente da sociedade internacional. Anomalia porque desafia a premissa de que todos os indivíduos pertencem a um estado, localizando-se à margem da relação estado - cidadão território. Inevitável porque não há como prevenir todas as possibilidades de falha de proteção do estado que causem movimentos involuntários de indivíduos através de fronteiras. Permanente porque, enquanto houver fronteiras separando todo o território em estados soberanos, sempre haverá indivíduos no espaço entre esses soberanos (HADDAD, 2008).

No caso dos deslocados internos, outra lógica rege a definição da categoria e as ações voltadas à sua proteção internacional. Por permanecerem dentro das fronteiras do estado, não se configura uma quebra da relação fundamental entre 
cidadania e territorialidade. Tampouco há uma ameaça clara à estabilidade internacional, se comparada a movimentos massivos em direção a outros estados. O envolvimento internacional com deslocados internos, portanto, é produto de decisão, e não de uma anomalia inevitável.

Quando dos primeiros debates sobre a definição de deslocados internos e as modalidades de envolvimento internacional, no final dos anos 80 , grande parte das fronteiras já estava fixada e protegida pelos corolários de respeito e não-intervenção. Não houve ameaça iminente à ordem internacional que determinasse um envolvimento continuado dentro das fronteiras e a criação de uma nova categoria de proteção. O que houve foi uma determinação voluntária dos estados, juntamente com ONGs e burocracia internacional, de "considerar a necessidade de se estabelecer, no sistema das Nações Unidas, um mecanismo ou arranjo que assegure a implementação e coordenação geral de programas de assistência para os deslocados internos" ${ }^{\prime 44}$.

Esse fato faz dos deslocados internos uma categoria única não apenas em relação aos refugiados, mas também a qualquer outro grupo vulnerável. Cabe lembrar que nunca houve demanda interna organizada pela criação da norma de proteção, como normalmente ocorre em casos de proteção internacional a minorias. Os instrumentos internacionais que versam sobre os direitos das mulheres, crianças, indígenas, população negra, LGBT e mesmo migrantes foram resultado de pressão de grupos organizados que representavam os interesses dessas populações (ALSTON; STEINER, 2007).

Já as populações deslocadas não se reconheciam como grupo vulnerável nem como sujeitos de direitos e de garantias específicas. Vítimas de deslocamento forçado no Sudão, por exemplo, não se viam como semelhantes, em condição ou direito, àquelas na Colômbia, Sri Lanka ou Ruanda. Não houve, portanto, agência dos deslocados internos no processo de definição das necessidades de proteção ou da criação da norma internacional. A categoria foi criada pela sociedade internacional e de sua estrutura derivaram os direitos, políticas e ações de proteção que atualmente beneficiam e empoderam os deslocados internos.

\section{CONSIDERAÇÕES FINAIS}

O presente artigo buscou demostrar o breve caminho percorrido pelos deslocados internos para sua afirmação como categoria internacional de prote-

44 UN GENERAL ASSEMBLY. International Conference on the Plight of Refugees, Returnees and Displaced Persons in Southern Africa: Report of the Secretary-General. 28 set. $1989, \mathrm{~A} / 44 / 520$. 
ção. Esse caminho partiu da completa inexistência da categoria nos anos 70 , passou pela identificação das "pessoas deslocadas" como meros refugiados em potencial nos anos 80 , chegou no reconhecimento das vulnerabilidades específicas e necessidades especiais de proteção dos deslocados internos nos 90 e, por fim, culminou no estabelecimento de uma categoria sólida de amplo reconhecimento e titular de direitos e de prerrogativas de proteção presentes em normativa interna e internacional.

Esse caminho, trilhado primordialmente no âmbito de organizações multilaterais e por iniciativa de atores internacionais, faz dos deslocados in- ternos uma categoria única e típica da sociedade internacional. Diferentemente dos refugiados, cujo cruzamento de fronteiras demandava um claro envolvimento internacional em sua proteção, os deslocados internos permanecem dentro das fronteiras de seus países, não configurando uma quebra da relação fundamental entre cidadania e territorialidade. O envolvimento internacional com grupo é, portanto, produto de uma decisão positiva, gestada no âmbito das Nações Unidas em razão da magnitude global do problema e do progressivo reconhecimento dos deslocados internos como grupo específico numa abordagem de direitos humanos.

\section{REFERÊNCIAS}

ALSTON, P.; STEINER, H. International Human Rights in Context: Law, Politics, Morals, Oxford: Oxford University, 2007.

BARKIN, J. S.; CRONIN, B. The State and the Nation: changing norms and the rules of sovereignty in international relations. International Organization, v. 48, n. 1, p. 107130, 1994.

BETTS, A. Comprehensive Plans of Action: insights from CIREFCA and the Indochinese CPA. New Issues in Refugee Research, 2006. Disponível em: <http://www.refworld. org/pdfid/4ff163c82.pdf>. Acesso em: dez. 2013.

BETTS, A.; LOESCHER, G. Refugees in International Relations, In: (Ed.). Refugees in International Relations. Oxford: Oxford University Press, 2011. p. 1-25.

BEYANI, C. Protection of the Right to Seek and Obtain Asylum under the African Human Rights System. The Hague: Brill/Nijhoff, 2013.

BRADLEY, M.; ASPLET, M. Strengthened Protection for Internally Displaced Persons in Africa: the Kampala Convention comes into force. 6 dez. 2012. Disponível em: <http:// 
www.brookings.edu/research/articles/2012/12/06-africa-kampala-bradley>. Acesso em: dez. 2013.

BULL, H. A Sociedade Anárquica, Brasília, UnB/IPRI, 2002.

BUZAN, B. From International to World Society? English School Theory and the Social Structure of Globalization, Cambridge: Cambridge University Press, 2004.

CERNEA, M. Development-induced and Conflitc-Induced Displacament: bridging the research devide. Forced Migration Review Special Edition, p. 25-27, 2006.

COHEN, R.; DENG, F. M. Masses in Flight: the global crises of internal displacement. Washington, DC: Brookings Institution, 1998.

DENG, F.; MACNAMARA, F. International and National Responses to the Plight of IDPs. Forced Migration Review, n. 10, p. 24-27, 2001.

FELLER, E. UNHCR's role in IDP protection: opportunities and challenges, Forced Migration Review Special Issue, p. 11-13, 2006.

GOODWIN-GILL, G. The Refugee in International Law. Oxford: Oxford University Press, 1996.

HADDAD, E. The Refugee in International Society: Between Sovereigns. Cambridge: Cambridge University Press, 2008.

JACKSON, R. H. Boundaries and International Society, In: ROBERSON, B.A. (Ed.). International Society and the Development of International Relations Theory. London, Continuum, 2002. p. 156-172.

KALIN, W. The Guiding Principles on Internal Displacement: Annotations, 2008. Disponível em: $<$ http:// www.brookings.edu/research/reports/2008/05/spring-guiding-principles>. Acesso em: dez. 2013. . The Guiding Principles on Internal Displacement: Introduction. International Journal of Refugee Law, v. 10, n. 3, p. 557-562, 1998.

LOESCHER, G. Beyond Charity: International Cooperation and the Global Refugee Crisis. Oxford: Oxford University Press, 1996.

LOESCHER, G.; DOWNTY, A. Refugee Flows as Grounds for International Action. International Security, v. 21, n. 1, p. 43-71, 1996.

MARTIN, S. et al. The Uprooted: Improving Humanitarian Responses to Forced Migration. Lanham: Lexington Books, 2005.

MOONEY, E. The Concept of Internal Displacement and the Case for Internally Displaced Persons as a Category of Concern, Refugee Studies Quarterly, v. 24, n. 3, p. 9-26, 2005.

NOGUEIRA, M. B.; EFSTATHOPOULOS, C. Colombia Test Cases Strengthen IDP Protection. Forced Migration Review, v. 28, p. 44-5, 2007.

NOGUEIRA, M. B. Proteção aos Deslocados Internos e o Direito à As- 
sistência Humanitária: Caminhos Convergentes. In: JUBILUT, L.; APOLINÁRIO, S. M. O. S. (Ed.). Assistência e Proteção Humanitária Internacionais: aspectos teóricos e práticos. São Paulo: Quartier Latin, 2012.

ORCHARD, P. Protection of Internally Displaced Persons: soft-law as a norm generating mechanism, $R e$ view of International Studies, v. 36, n. 2, p. 281-303, 2010.

PHUONG, C. The International Protection of Internally Displaced Persons. Cambridge: Cambridge University Press, 2004.

WATSON, A. A evolução da sociedade internacional: Uma análise histó- rica comparativa. Brasília: Editora Universidade de Brasília, 2004.

WEISS, T. G.; KORN, D. A. Internal Displacement: conceptualization and it consequences. New York, Routledge, 2006. p. 9.

WEISS, T. G. Military-Civilian Interactions: Humanitarian Crises and the Responsibility to Protect, 2 ed. Lanham, MD: Rowman \& Littlefield Publishers, 2005.

WILLIAMS, J. New spaces, new places: solidarism, pluralism and territoriality. Paper presented at the 2011 British International Studies Association Conference, 2011. Disponível em: $<$ http://isanet.ccit. arizona.edu/noarchive/williams1. html>. Acesso em: dez. 2013. 